\title{
Cystic and florid squamous metaplasia in pleomorphic adenoma of palate - A diagnostic dilemma
}

\author{
Kaveri $\mathbf{H}^{1}$, Gopalkrishnan $\mathrm{K}^{2}$, Venkatesh Anehosur ${ }^{2}$ \\ ${ }^{1}$ Department of Oral and Maxillofacial Pathology, ${ }^{2}$ Department of Oral \& Maxillofacial Surgery, D.M. College of Dental Sciences \& Hospital, \\ Dharwad, Karnataka - 580009, India
}

\section{A B S T R A C T}

\begin{abstract}
Pleomorphic adenoma is a benign tumor of salivary gland. Controversy regarding the origin of various mesenchymal components exists and myoepithelial cell has a key role. Metaplastic process is triggered by minor trauma and probable etiology for this change is ischemia. It is diagnostically challenging, because diagnostic pit falls in the presence of mucinous and squamous metaplasia. Report a case of pleomorphic adenoma in the palate of a 35 years old Indian female. Biopsy revealed epithelial component with extensive squamous metaplasia and cystic degeneration. Here we discuss the role of myoepithelial cells in the pathogenesis of pleomorphic adenoma and diagnostic pit falls.
\end{abstract}

Access this article online

Website:

http://nepjol.info/index.php/AJMS

Key words: Myoepithelial cell, pleomorphic adenoma, squamous metaplasia

\section{INTRODUCTION}

Pleomorphic adenoma is a benign epithelial neoplasm of salivary gland, histopathologically characterized by a great diversity of morphological aspects. ${ }^{1}$ Intercalated duct and myoepithelial cells determine the pleomorphic structure of the tumor. Controversy regarding the origin of various mesenchymal components pleomorphic adenoma, it is now well accepted that myoepithelial differentiation is predominant in these tumors and responsible for their morphologic diversity. ${ }^{2}$ Myoepithelial cell has a key role in the genesis of these tumors, being capable of dedifferentiation, metaplasia and transdifferentiation. ${ }^{3}$ This case illustrates the difficulty of making a correct diagnosis in the initial tissue specimen and adding a note on diagnostic pitfalls of this pathological entity.

\section{CASE REPORT}

A 35 years female presented with swelling in the palate since 2 years, but the increase in the size is observed in last 3 months. Physical examination revealed a well defined growth on the hard palate extending from incisive foramen up to the middle of hard palate. Irregular in shape, soft in consistency and size of the tumor is $50 \times 50 \mathrm{~mm}$ measuring antero-posteriorly and mediolaterally (Figure 1). Pleomorphic adenoma was the provisional diagnosis. Computed tomography scan reveals soft tissue tumor mass with complete destruction of turbinates (Figure 2).

Incisional biopsy was performed that revealed clusters of slightly atypical squamous cells with nuclei and moderate amount of eosinophilic cytoplasm with evidence keratin pearl formation. These squamous cells were seen lining the cystic spaces. The connective tissue component was very minimal. Possibility of pleomorphic adenoma and low grade mucoepidermoid carcinoma or well differentiated squamous cell carcinoma was considered. Considering the differential diagnosis, the lesion was surgically excised. Exicisional specimen revealed squamous cells with extensive squamous metaplasia and keratin pearl formation (Figure 3). Multiple cystic spaces of varying sizes were lined by squamous cells (Figure 4). There were no mucin containing cells and the absence of malignant features ruled the mucoepidermoid carcinoma and well differentiated squamous cell carcinoma. The stroma was fibrous, with lipometaplasia and lymphocytic infiltration is evident. Minimal myxoid stroma was observed. The diagnosis of 
pleomorphic adenoma with extensive squamous metaplasia and cystic degeneration was made. Patient responded well with treatment and post operative palatal obturator was given covering the exposed area (Figure 5).

\section{DISCUSSION}

Salivary gland neoplasia is unique encompassing perhaps the most complex histopathology of any organ system. The occurrence of pleomorphic adenoma in parotid, submandibular and intra oral salivary gland is $66-77 \%$, $45-60 \%$ and $19-53 \%$ respectively. ${ }^{1}$

Two types of cells determine the pleomorphic structure of the tumor, an inner row of the epithelial cells and an outer layer of myoepithelial cells. The great diversity of cytological differentiation present in pleomorphic adenoma can be explained by metaplastic potential of the neoplastic myoepithelial cells. ${ }^{2}$

Myoepithelial cells are the result of the differentiation of the pluripotent cells from the salivary ducts during the $10^{\text {th }}$ week of embryo life but in adult life they may proceed from the reserve cells of the intercalated and striated salivary ducts. These myoepithelial cells have the ability to transdifferentiate into cells of the mesenchymal line. The modified myoepithelial cells derived from the neoplastic myoepithelial cells as a result of metaplasia, differentiation and transdifferentiation processes., ${ }^{2,3}$

Squamous metaplasia is uncommon and incidental microscopic finding in benign salivary gland tumors. But squamous metaplasia has been noted in non neoplastic entities like chronic sialadenitis, necrotizing sialometaplasia and lymphoepithelial cyst. ${ }^{4}$ This change is commonly associated with repair following infarction and necrosis of the salivary glands. The metaplastic process might occur spontaneously or be triggered by minor trauma. The most probable etiology for this change is ischemia. This etiology is supported experimentally by the induction of squamous metaplasia in rat salivary glands by arterial ligation. ${ }^{4}$ The varying degree of squamous metaplasia is because of rapidity and ease of the switch in genetic programming of cytokeratin filaments induced by ischemia in salivary glands. ${ }^{5}$

$25 \%$ of pleomorphic adenoma shows some degree of squamous metaplasia and this process appears to arise largely in relation to modified myoepithelial cells. The squamous differentiation in mucoepidermoid carcinoma is either by the luminal epithelial or modified myoepithelial cells. ${ }^{6-8}$

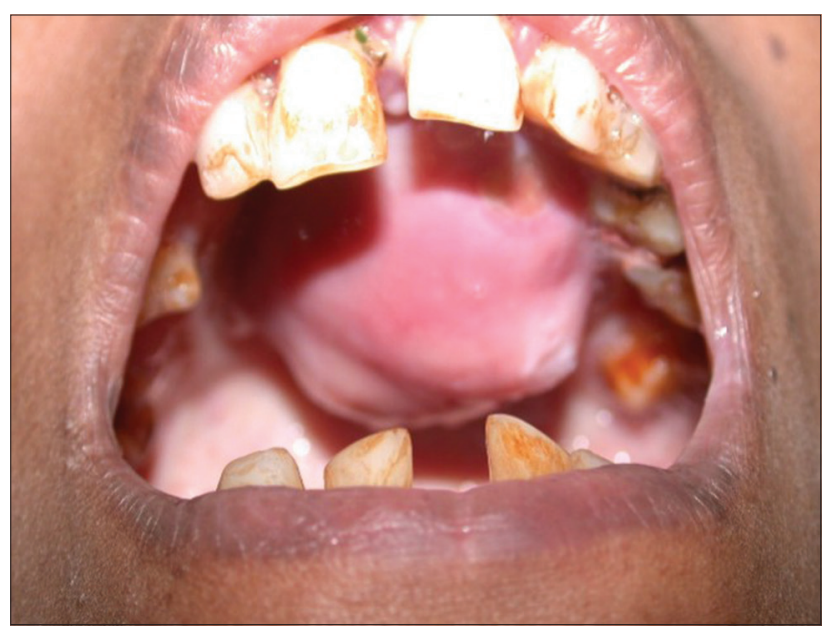

Figure 1: Palatal swelling involving the whole palate with intact surface mucosa

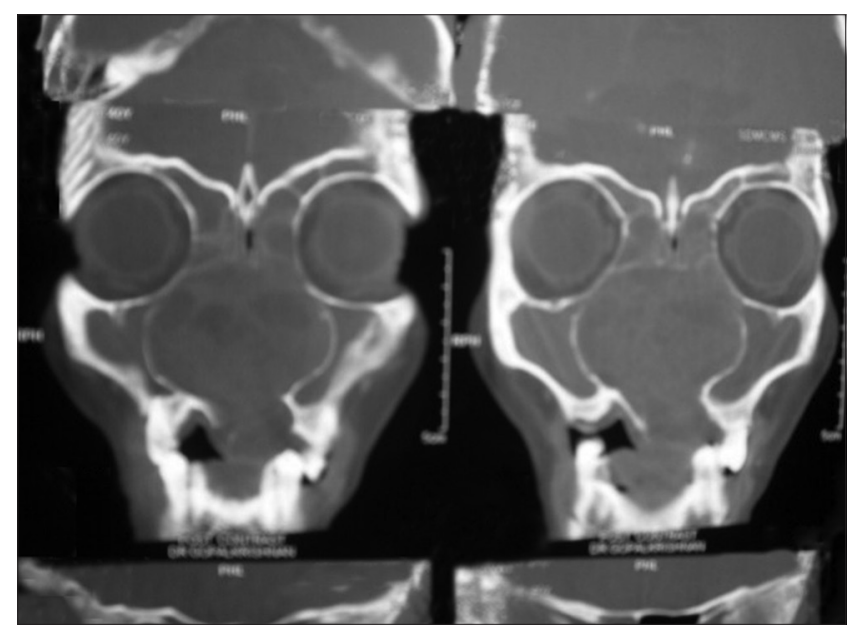

Figure 2: Computed tomography scan reveals soft tissue tumor mass with complete destruction of turbinates

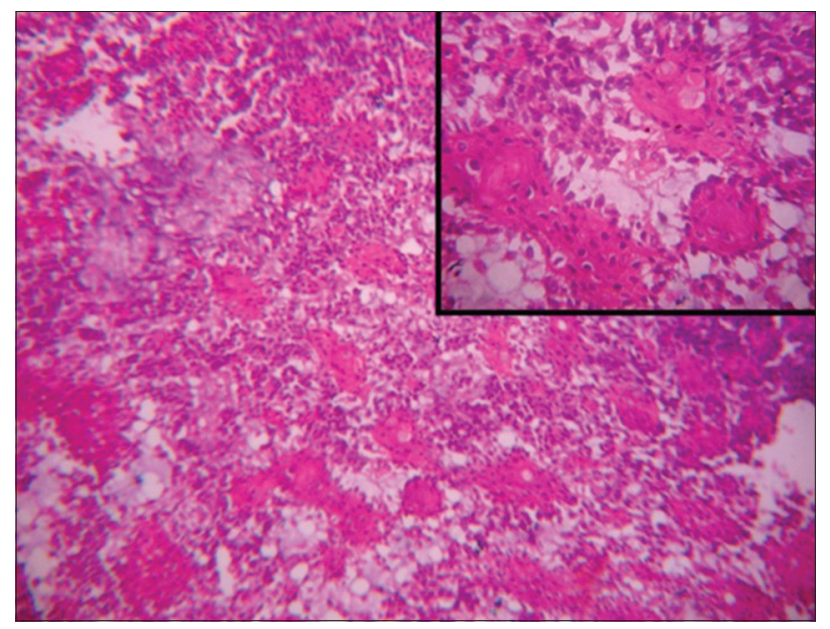

Figure 3: Epidermoid differentiation with keratinization occurring in sheet like areas of tumor cells ( $H \& E$ stain $\times 50)$, Inset shows squamous cells with keratin form of pearl. $(H \& E, \times 100)$ 


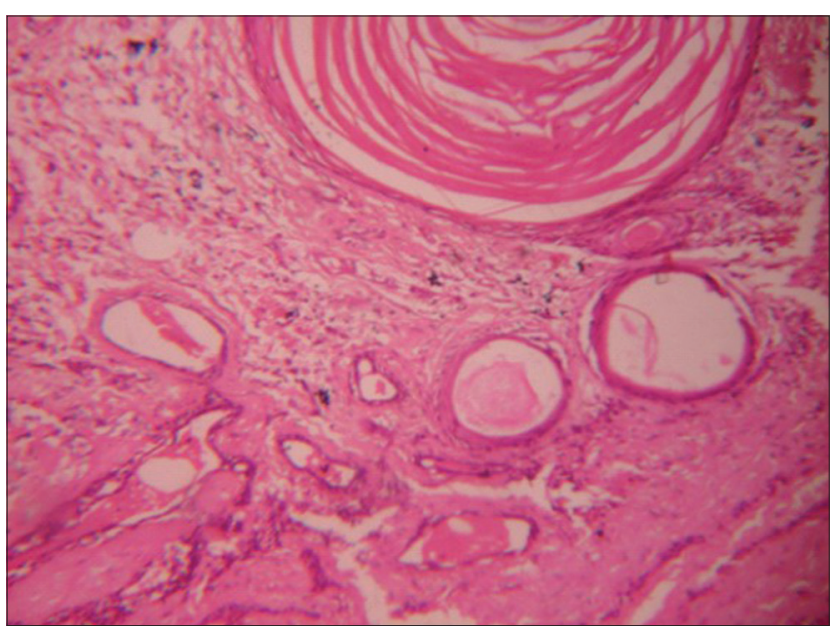

Figure 4: Photomicrograph showing cysts containing keratin and mucin like content $(H \& E$ stain $\times 50)$

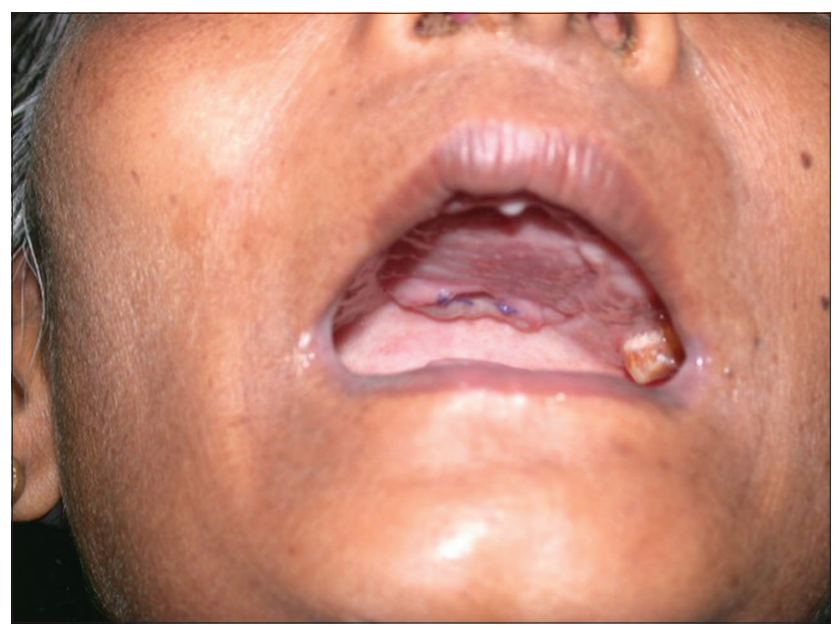

Figure 5: Post operative photograph with palatal obturator covering the exposed area

The marked ability of acinar units in rat salivary gland to undergo squamous metaplasia lends further support to this premise and provides new evidence for histogenic pathways in human salivary gland tumors. ${ }^{7}$

Squamous metaplastic changes seen in benign salivary glands might lead difficulties or misdiagnosis through FNAB and intraoral frozen section simulating malignant neoplasm probably high grade mucoepidermoid carcinoma and squamous cell carcinoma. The probable reasons are the squamous cells often reveal nuclear atypia and the scanty mesenchymal component in pleomorphic adenoma. This may have direct effect on preoperative and intra operative surgical planning in surgery of the tumors. ${ }^{9,10}$

\section{CONCLUSION}

In conclusion, the feature of squamous metaplasia raises the possibility of carcinoma or carcinomatous even though these are related to ischemia as proven in the experiments. Awareness of these changes is important to prevent over interpretation of benign salivary tumors while excluding other malignancies.

\section{REFERENCES}

1. Gary L. Ellis, Paul L. Auclur, Douglas R. Gnepp. W.B Sounders Company. Surgical Pathology of the Salivary Glands. $3^{\text {rd }}$ Ed. Saunders, 1991, P-166.

2. Adnan $T S$ and Richard J Z. Defining the role of myoepithelium in salivary gland neoplasia. Adv Anat Pathol 2004; 11: 69-85.

3. Dardick I, Jeans MT, Sinnott NM, Wittkuhn JF, Kahn HJ and Baumal R. Salivary gland components involved in the formation of squamous metaplasia. Am J Pathol 1985; 119:33-43.

4. Dardick I, Jeans D, Sinnnott NM, Wittkuhn JF, Khan HJ and Baumal R. Salivary gland components involved in the formation of squamous metaplasia. Am J Pathol 1985; 119: 33-43.

5. Dardick I, van Nostard AWP and Phillips MJ. Histogenesis of Salivary gland pleomorphic adenoma with an evaluation of the role of the myoepithelial cell. Hum Pathol 1982; 13: 60-75.

6. Taxy J B. Necrotizing squamous/mucous metaplasia in oncocytic salivary gland tumor. A potential diagnostic problem. Am J Clin Pathol 1992; 97: 40-45.

7. Lam KY, Ng IOL and Chan GSW. Palatal pleomorphic adenoma with florid squamous metaplasia: a potential diagnostic pitfall. J Oral Pathol Med 1998; 27: 407-410.

8. Hamdan K, Maly B, Elashar R and Gross M. Mucinous and squamous metaplasia in benign tumors of parotid gland: A potential pitfall in the diagnosis. Otolarygol Head Neck Surg 2005; 133: 987-988.

9. Viguer JM, Vincandi B and Jimenez-Heffernan JA. Fine needle aspiration cytology of pleomorphic adenoma: an analysis of 212 cases. Acta Cytol 1997; 41: 786-794.

10. Hamdan K, Maly B, Elashar R and Israel M. Mucinous and squamous metaplasia in benign tumors of the parotid gland: A potential pitfall in the diagnosis. Otolaryngol Head Neck Surg 1985; 133: 987-988.

\footnotetext{
Authors Contribution:

HK, KG, VA - the manuscript preparation.

Source of Support: Nil, Conflict of Interest: None declared.
} 